\title{
Comparing the Effect of Age, Gender, and Desired Speed on Car-Following Behavior by Using Driving Simulator
}

\author{
Ehsan Ramezani-Khansari $\mathbb{D}^{1},{ }^{1}$ Masoud Tabibi $\mathbb{D}^{2},{ }^{2}$ Fereidoon Moghadas Nejad $\mathbb{D},{ }^{1}$ \\ and Mahmoud Mesbah (iD) \\ ${ }^{1}$ Civil Engineering Department, Amirkabir University of Technology (Tehran Polytechnic), Tehran, Iran \\ ${ }^{2}$ Road Traffic Injury Research Center, Tabriz University of Medical Sciences, Tabriz, Iran \\ Correspondence should be addressed to Ehsan Ramezani-Khansari; e.r.khansari@aut.ac.ir
}

Received 30 March 2021; Revised 23 July 2021; Accepted 14 August 2021; Published 19 August 2021

Academic Editor: Haneen Farah

Copyright (C) 2021 Ehsan Ramezani-Khansari et al. This is an open access article distributed under the Creative Commons Attribution License, which permits unrestricted use, distribution, and reproduction in any medium, provided the original work is properly cited.

In this study, the effect of age, gender, and desired speed (DS) factors on General Motors car-following (CF) behavior was investigated. DS was defined as the speed selected by the driver in free driving situation. A low-level driving simulator was used to collect data. The CF model for each driver was calibrated by genetic algorithm. Gender and DS were effective in CF behavior, while the age factor was not. The drivers' sensitivity to the variables of speed and distance in the CF model increased with increasing the DS. The gender factor affected only the magnitude of deceleration which was higher in women. For further investigation, the effect of the desired speed on the time headway in the steady-state CF was also examined. DS factor was effective in steady-state CF behavior. As the DS increased, the time headway decreased. Examining CF threshold demonstrated that women maintained larger distance than men. Finally, it can be said that DS and gender would be more important than age to be considered in CF models.

\section{Introduction}

Driving behavior can be influenced by the individual characteristics of the drivers and it has been studied in various aspects. Minh and Sano modeled acceleration and deceleration of motorcycles at signalized intersections. They applied a dummy variable for motorcyclist's gender which was finally appeared significant [1]. Analyzing the effects of drivers' characteristics such as age, gender, and driving style on fuel efficiency demonstrated that there was significant difference in the driving fuel efficiency, on the highway, depending on the age and gender. The results indicated that the fuel efficiency of late middle age drivers was higher than the younger ones and that of female drivers was higher than male drivers [2].

Car-following (CF) is one of the main driving behaviors in the traffic flow that describes longitudinal trajectory of a vehicle in a lane and its interaction with leading vehicle(s) to keep safe distance through throttle and braking [3, 4].
Studying the effect of individual characteristics on CF is important from macroscopic and microscopic view.

There are a lot of studies about the relationship between drivers' characteristics and road accidents [5-9]. Improper or unsafe CF behavior is one of the reasons of rear-end collision $[10,11]$. Thus, investigating CF can help to prevent and predict rear-end collision and also can enhance traffic safety. Several researches have confirmed that both the CF model and its estimated parameters can vary for different drivers and situations [12-17].

Ranny was one of the firsts to address the effect of individual characteristics on CF behavior. In addition to personal characteristics, including age, gender, marital status, and risk-taking, he also considered situational factors including time of day, weather, and type of roads to be effective [18]. Montgomery et al. found that gender and age (selecting 30 as the threshold) can affect time to collision at braking in following situation [19]. James and Hammit applied the trajectory data from the SHRP2 Naturalistic 
Driving Study to calibrate three CF models including Gipps, Intelligent Driver Model, and Wiedemann 99. They clustered estimated parameters of models based on different drivers' characteristics. Driver age, income, and marital status were found as important criteria for clustering while gender, work status, and living status were not [20].

Chiabaut et al. developed an effective estimation method to examine and calibrate interdriver heterogeneity in Newell's car-following model. They found that different drivers may have different reactions to the same stimulus [21]. Kim and Mahmasani calibrated several CF models by using Next Generation Simulation project (NGSIM) data and examined the estimated parameters for the models. Their results showed a statistically significant difference between the sets of correlated and uncorrelated estimated parameters [22]. van Hinsbergen calibrated Helly and General Motors CF models by applying Bayesian method. They found that driver behavior could be fitted by different models and that is there was heterogeneity in driver behavior [23]. Ranjitkar et al. recorded the trajectory of 9 vehicles on a test road using Global Positioning System (GPS) and tested different CF models. They found that the error variations obtained from different individuals were greater than the error resulting from the use of different models, which can be due to the drivers' heterogeneity [24]. Chen et al. used NGSIM data to calibrate the MITSIM and the Intelligent Driver Models. They observed that the estimated parameters formed a hyperplane, in which no specific classification was distinguished and the data were scattered, which could be interpreted as heterogeneity in drivers [25].

In many of previous studies, it has only demonstrated that different CF models and estimated parameters are appropriate for different drivers and thus there is heterogeneity in drivers which must be considered. But the effect of the each drivers' characteristics on heterogeneity was not investigated because of the lack of information about drivers, as the trajectory data had been extracted from recorded videos [26]. In this study, the effect of drivers' characteristics on CF behavior was investigated by using driving simulator data. Second section is dedicated to methodology. Data collection is introduced in the third section. Results and discussion are explained in the fourth section. Finally, section five concludes the research.

\section{Methodology}

A model is needed to investigate the effect of drivers' characteristics on CF behavior, thus General Motors CF model has been used, which is given by

$$
a_{n}(t)=c v_{n}^{m} \frac{\Delta v(t-\tau)}{\Delta x^{l}(t-\tau)},
$$

where $a_{n}(t)$ is the acceleration of subject vehicle at time $t$, $v_{n}(t)$ is the speed of the subject vehicle at time $t, t$ is the reaction time $(\tau=0.7 \mathrm{sec}[12]), \Delta v(t-\tau)$ is the relative speed at time $t$ minus $\tau, \Delta x(t-\tau)$ is the space headway at time $t$ minus $\tau, n$ is the vehicle index of the follower vehicle, and $c, 1$, $m$ are the parameters of the model.
Maximum following distance has been considered $90 \mathrm{~m}$. In other words, $90 \mathrm{~m}$ has been postulated as the threshold for starting car-following behavior and the trajectory data at longer distance have not been used and considered as free driving situation [27]. This model is one of the most wellknown CF models that is still used to study driving behavior. Although this model has disadvantages such as insensitivity to distance when two cars are at the same speed, simplicity and comprehensibility have led to it still being used in many studies.

The parameters for the acceleration and deceleration situations must be calculated separately [28, 29], and the focus of this paper is on the deceleration CF model. To compare the effect of drivers' characteristics on CF behavior, the model has been calibrated for the data of each participant by using a genetic algorithm. By doing so, three parameters of $c, \mathrm{~m}$, and $l$ have been obtained for each driver. These parameters can indicate the effects of magnitude of deceleration (sensitivity), speed, and distance in the CF model, respectively. Regarding the concept and effect of each variable, ranges have been considered for parameters: $c$ between 0 and $3, m$ between 0 and 1 , and $l$ between 1 and 2 .

From the personal characteristics, three factors of gender, age, and desired speed (DS) have been considered as drivers' characteristics. Age and gender have been evaluated in many previous studies. The DS was also added here to be examined as new factor. The DS has been defined the (average) speed selected by the driver in free driving mode. The DS may be an indicator for measuring the driver's aggression. Therefore, the difference in choosing the DS may spread to other driving behavior such as CF. To obtain the DS, all speeds recorded in free driving condition were gathered and then averaged out. Estimated parameters were categorized based on age, gender, and DS and were analyzed using statistical tests.

Given that gender was expected to be an important factor, at first, the data were separated by gender and then men group's data were categorized based on the age (over and under 35 years old) and DS (over and under $95 \mathrm{~km} / \mathrm{h}$ ) because there was more diversity in the men group. At the end, men and women's data were compared. One of the objectives of this research was to investigate the DS as an affecting factor on the CF behavior; therefore, for further investigation, the effect of the DS on the distance in steady-state CF has been discussed. In the steady-state CF, two consecutive vehicles in the same lane or path have almost the same and constant speed. Here, when the speed difference was less than $5 \mathrm{~km} / \mathrm{h}$, the speeds were considered equal $[30,31]$.

All data were extracted from leading and following vehicle trajectories in $0.1 \mathrm{sec}$ intervals. The use of driving simulator and its data for research purposes can raise the question of whether driving simulator data are sufficiently valid. The answer to this question itself requires research and experimentation in which real data are compared with simulator data and have been the subject of much research. There are studies that only validate driving simulator data for specific factors such as speed and distance [32-34]. Ramezani-Khansari et al. investigated the validation of driving simulator for CF behavior [35]. 


\section{Data Collection}

28 women and 126 men participated in the driving test. 4 men's data were dropped because of simulator sickness. The age ranges of female and male drivers were between 19 and 28 and between 18 and 58, respectively. Figures 1 and 2 show the age distribution of drivers for each gender. The characteristics of participants are mentioned in Table 1.

The test time of each participant was divided into two parts, which are

Warm Up. In this step, the driver drove completely freely to adapt to the driving simulator. Warm up was considered about 5 to 10 minutes. This time could vary according to the age and ability of the participants and ended with their signal [36]. At the end of the warm up, she/he was asked to stop the car and rest for a few minutes in order to get ready for driving test.

Driving Test: In main driving, participants drove about 10 to 15 minutes on a highway.

\section{Results and Discussion}

First, the effect of age and DS factors in the men group was investigated. Then, the CF behavior between men and women was compared. Finally, different GM CF models were presented considering the effect of factors. Furthermore, time headway in steady-state CF was investigated based on the DS.

4.1. Age and Desired Speed Factors. To evaluate the effect of age on CF behavior, men were divided into over and under 35 years, young, and midage subgroups, respectively. The results of two-sample $t$-test (Table 2) showed that $P$ value was greater than 0.05 for all parameters and the statistical test could not reject the null hypothesis (equality of means). Therefore, it can be inferred there is no significant difference between the estimated parameters of young and midage groups in male drivers. In other words, age would have no effect on CF behavior and it cannot be a factor for classifying drivers. So, DS was studied as an affecting factor. Participants' DSs were between 75 and $115 \mathrm{~km} / \mathrm{h}$.

Male drivers were divided into two categories of over and under $95 \mathrm{~km} / \mathrm{h}$ (median of DS data) based on the DS. Table 3 examines the difference between the parameters of CF model between the two DS groups of men.

The results of two-sample $t$-test of three parameters showed that the difference between men's DS groups would be significant. In other words, it can be said that the classification based on the DS can express the differences in CF behavior.

Given that the statistical test showed there would be a significant difference in the classification based on the DS, the question arises whether drivers in a certain age group tend to a certain DS. The age distributions of drivers for the DS groups, upper and lower $95 \mathrm{~km} / \mathrm{h}$, are depicted in Figures 3 and 4 . They intuitively show no difference.

The statistical test in Table 4 shows that there would be no significant difference between the two men's DS groups. So,

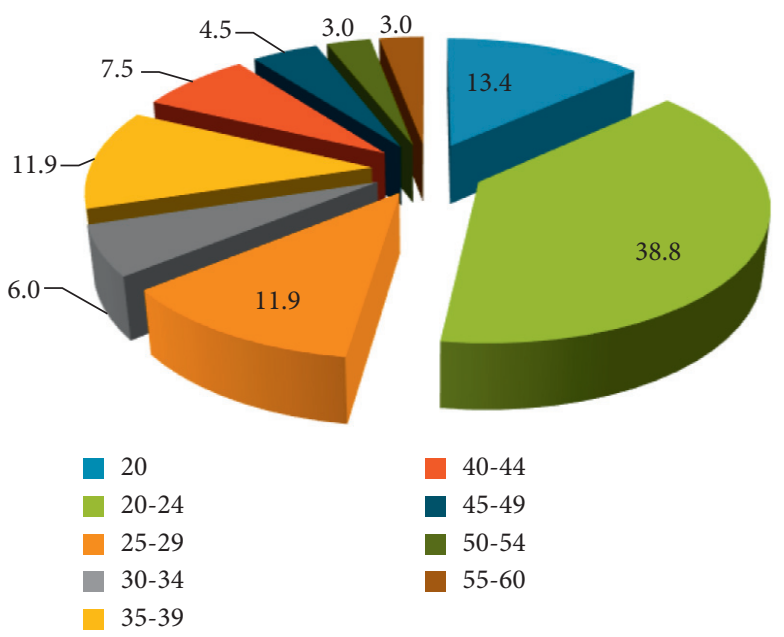

FIgURE 1: Age distribution of male drivers participating in driving simulator.

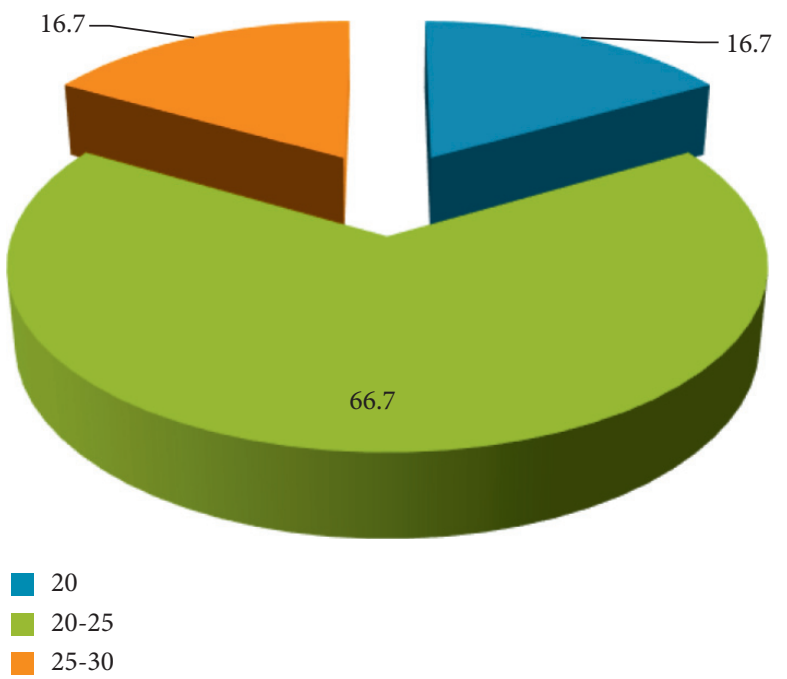

FIgURE 2: Age distribution of female drivers participating in driving simulator.

TABLE 1: The characteristics of participants.

\begin{tabular}{lccc}
\hline & Age $^{*}$ & Gender & Desired speed \\
\hline Mean & 30.32 & 0.87 & 88.37 \\
Standard error & 1.38 & 0.04 & 1.22 \\
Median & 26.00 & 1.00 & 89.00 \\
Mode & 21.00 & 1.00 & 97.00 \\
Standard deviation & 10.89 & 0.34 & 9.58 \\
Min. & 18.00 & 0.00 & 70.00 \\
Max. & 58.00 & 1.00 & 121.00 \\
\hline
\end{tabular}

${ }^{*}$ Age: $\operatorname{man}=1$ and woman $=0$.

the DS would be a factor independent of the age, and the DS would not increase or decrease by increasing the age of driver.

4.2. Gender Factor. After examining the age and DS factors, the gender factor has been discussed. The maximum DS in the women's group was $95 \mathrm{~km} / \mathrm{h}$. Hence, 
TABLE 2: Two-sample $t$-test of CF parameters between the men groups categorized based on age.

\begin{tabular}{|c|c|c|c|c|c|c|}
\hline & \multicolumn{2}{|c|}{$c$} & \multicolumn{2}{|c|}{$m$} & \multicolumn{2}{|c|}{$l$} \\
\hline & Age $<35$ & Age $>35$ & Age $<35$ & Age $>35$ & Age $<35$ & Age $>35$ \\
\hline Mean & 0.5269 & 0.4602 & 0.2277 & 0.2580 & 1.1360 & 1.164 \\
\hline Variance & 0.1106 & 0.1150 & 0.0683 & 0.0926 & 0.0437 & 0.045 \\
\hline$P(T \leq t)$ one-tail & 0.3574 & & 0.2612 & & 0.2221 & \\
\hline$t$ critical one-tail & 1.6549 & & 1.6547 & & 1.6551 & \\
\hline$P(T \leq t)$ two-tail & 0.7148 & & 0.5224 & & 0.4442 & \\
\hline$t$ critical two-tail & 1.9756 & & 1.9753 & & 1.9761 & \\
\hline
\end{tabular}

TABLE 3: Two-sample $t$-test of CF parameters of the model between the men groups categorized based on DS.

\begin{tabular}{|c|c|c|c|c|c|c|}
\hline & \multicolumn{2}{|c|}{$c$} & \multicolumn{2}{|c|}{$m$} & \multicolumn{2}{|c|}{$l$} \\
\hline & $\mathrm{DS}<95 \mathrm{~km} / \mathrm{h}$ & $\mathrm{DS}>95 \mathrm{~km} / \mathrm{h}$ & $\mathrm{DS}<95 \mathrm{~km} / \mathrm{h}$ & $\mathrm{DS}>95 \mathrm{~km} / \mathrm{h}$ & $\mathrm{DS}<95 \mathrm{~km} / \mathrm{h}$ & $\mathrm{DS}>95 \mathrm{~km} / \mathrm{h}$ \\
\hline Mean & 0.3357 & 0.8487 & 0.2697 & 0.1758 & 1.1081 & 1.2022 \\
\hline Variance & 0.0216 & 0.2618 & 0.0870 & 0.0495 & 0.0334 & 0.0568 \\
\hline$P(T \leq t)$ one-tail & 0.0012 & & 0.0209 & & 0.0033 & \\
\hline$t$ critical one-tail & 1.6547 & & 1.6547 & & 1.6547 & \\
\hline$P(T \leq t)$ two-tail & 0.0026 & & 0.0419 & & 0.0066 & \\
\hline$t$ critical two-tail & 1.9753 & & 1.9753 & & 1.9753 & \\
\hline
\end{tabular}

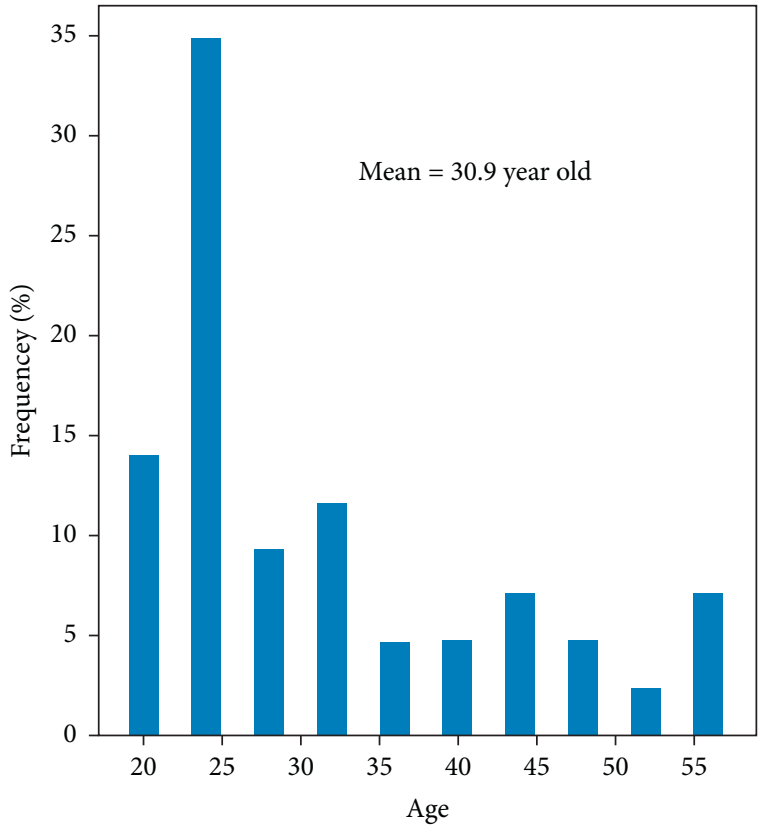

FIGURe 3: Age distribution of male drivers with DS under $95 \mathrm{~km} / \mathrm{h}$.

the women group was compared to men group with DS lower than $95 \mathrm{~km} / \mathrm{h}$ (Table 5), because it was demonstrated in the previous section that the DS can be an important factor.

The two parameters $m$ and $l$ did not show a significant difference, while the parameter $c$ was significantly higher in the group of women (roughly 2 times larger). The $m, l$, and parameters indicate the driver's sensitivity to the speed, distance, and magnitude of deceleration between the two vehicles, respectively. In other words, the gender factor only affected the magnitude of deceleration.

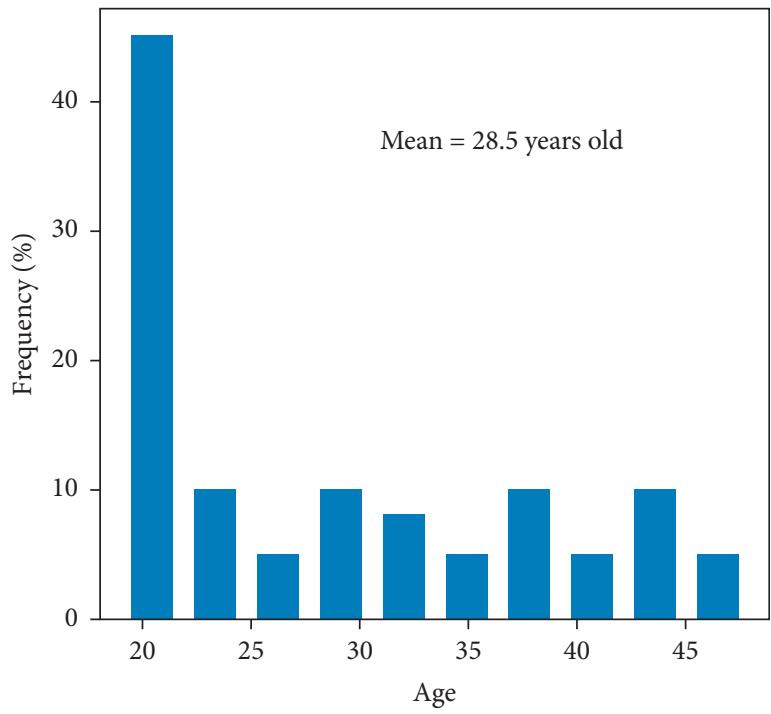

FIgURE 4: Age distribution of male drivers with DS over $95 \mathrm{~km} / \mathrm{h}$.

TABLE 4: Two-sample $t$-test of driver age between men's DS groups.

\begin{tabular}{lcc}
\hline & DS $<95$ & DS $>95$ \\
\hline Mean & 30.9 & 28.5 \\
Variance & 121.62 & 93.10 \\
$P(T \leq t)$ one-tail & 0.1457 & \\
$t$ critical one-tail & 1.6526 & \\
$P(T \leq t)$ two-tail & 0.2914 & \\
$t$ critical two-tail & 1.9721 & \\
\hline
\end{tabular}

4.3. Desired Speed and Time Headway. To investigate whether the DS is effective in other aspects of CF behavior, the relationship between time headway $(\mathrm{TH})$ in steady-state $\mathrm{CF}$ and DS was studied. Moreover, it was compared with the 
TABLE 5: Two-sample $t$-test of CF parameters between men and women groups.

\begin{tabular}{|c|c|c|c|c|c|c|}
\hline \multirow{2}{*}{$\begin{array}{l}\text { Parameters } \\
\text { Gender } \\
\text { group }\end{array}$} & \multicolumn{2}{|r|}{$c$} & \multicolumn{2}{|c|}{$m$} & \multicolumn{2}{|r|}{$l$} \\
\hline & Men & Women & Men & Women & Men & Women \\
\hline Mean & 0.3357 & 0.7524 & 0.2697 & 0.2855 & 1.1081 & 1.0844 \\
\hline Variance & 0.2313 & 0.2116 & 0.0870 & 0.1433 & 0.0334 & 0.0367 \\
\hline $\begin{array}{l}P(T \leq t) \\
\text { one-tail }\end{array}$ & 0.0084 & & 0.4036 & & 0.2661 & \\
\hline $\begin{array}{l}t \text { critical } \\
\text { one-tail }\end{array}$ & 1.6573 & & 1.6564 & & 1.6564 & \\
\hline $\begin{array}{l}P(T \leq t) \\
\text { two-tail }\end{array}$ & 0.0169 & & 0.8073 & & 0.5323 & \\
\hline $\begin{array}{l}t \text { critical } \\
\text { two-tail }\end{array}$ & 1.9794 & & 1.9780 & & 1.9780 & \\
\hline
\end{tabular}

effect of age on the TH. It should be mentioned to avoid the effect of gender; men's TH data were used in this section. Figure 5 shows the relationship between age and TH in the male group. It can be seen that there is no relationship between them.

Figure 6 shows that the TH decreased as the DS increased. Table 6 shows that there would be a significant correlation between DS and TH $(P$ value $<0.05)$.

4.4. Car-Following Models by considering Heterogeneity Factors. It was observed that two factors, gender and DS, were effective in CF behavior. The estimated CF parameters for all participants were averaged and then categorized based on the gender and DS, so three GM models were provided (Table 7).

For instance, based on the values of the estimated parameters, it is possible to draw a graph of deceleration based on distance. Now, it is possible to draw the graphs of $\mathrm{CF}$ models based on distance. Given that there are three independent variables in the GHR model, two variables must be considered fixed in order to draw a two-dimensional diagram. Therefore, the speed of the following vehicle and relative speed between two consecutive vehicles were considered $90 \mathrm{~km} / \mathrm{h}$ and $20 \mathrm{~km} / \mathrm{h}$, respectively. By doing so, the relationship between deceleration and distance variable is plotted in Figure 7.

Figure 7 shows that the women applied greater deceleration than the men. In the men group, increasing the DS led to increasing the deceleration at an identical distance. In the figure, the acceleration values are negative and the sign is ignored.

Generally speaking, higher DS and female gender would lead to more aggressive behavior in deceleration CF behavior as they have led to intense deceleration. Moreover, it was observed that by increasing DS, the TH in steady-state CF was increased which would be an indicator for aggressive and unsafe behavior. According to the CF diagrams, it can be seen that gender and DS factors would be also effective in other driving behaviors.

Here, $0.5 \mathrm{~m} / \mathrm{s}^{2}$ was considered as the threshold of sensible deceleration which the driver applied intentionally (AASHTO; consider $-3.4 \mathrm{~m} / \mathrm{s}^{2}$ as comfortable deceleration

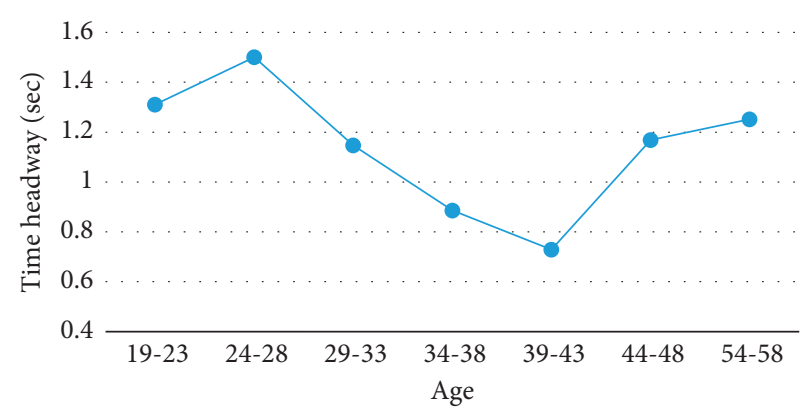

Figure 5: Relationship between $\mathrm{TH}$ and age of drivers in steadystate CF.

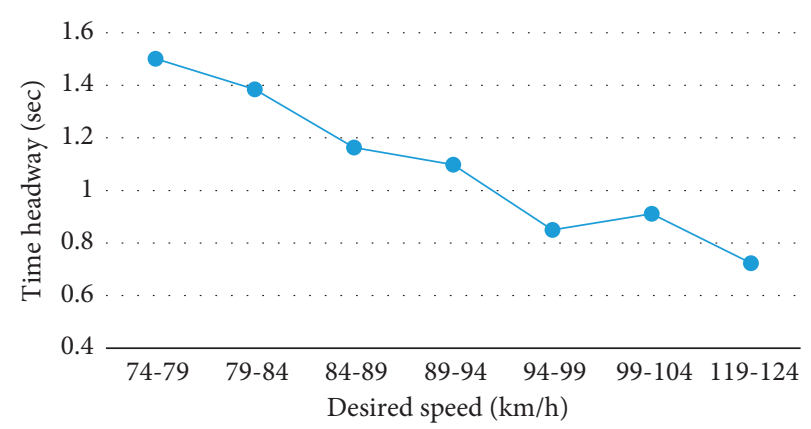

Figure 6: Relationship between TH and DS of drivers in steadystate CF.

TABle 6: Pairwise Pearson correlations of age-TH and DS-TH.

\begin{tabular}{lcccc}
\hline Sample 1 & Sample 2 & Correlation & $95 \%$ CI for $\rho$ & $P$ value \\
\hline $\begin{array}{l}\text { Time } \\
\text { headway }\end{array}$ & $\begin{array}{c}\text { Desired } \\
\text { speed }\end{array}$ & -0.965 & $\begin{array}{c}(-0.994, \\
-0.813)\end{array}$ & $\leq 0.001$ \\
\hline $\begin{array}{l}\text { Time } \\
\text { headway }\end{array}$ & Age & -0.156 & $\begin{array}{c}(-0.775, \\
0.616)\end{array}$ & 0.712 \\
\hline
\end{tabular}

TABle 7: The CF parameters based on gender and DS.

\begin{tabular}{lccc}
\hline & $c$ & $m$ & $l$ \\
\hline Man and DS $>95 \mathrm{~km} / \mathrm{h}$ & 0.3357 & 0.2697 & 1.1081 \\
Man and DS $<95 \mathrm{~km} / \mathrm{h}$ & 0.848 & 0.1758 & 1.2022 \\
Woman and DS $<95 \mathrm{~km} / \mathrm{h}$ & 0.752 & 0.2855 & 1.08447 \\
\hline
\end{tabular}

[37]). In other words, decelerations less than $0.5 \mathrm{~m} / \mathrm{s}^{2}$ have been accidentally happened, because even in free driving situation, the driver cannot adjust her/his speed precisely and there is a fluctuation. Therefore, the threshold of CF behavior, which was assumed to be $90 \mathrm{~m}$ in this study, can be estimated.

Examining Figure 7, it can be seen that the CF diagrams of men and women at points 30 and $50 \mathrm{~m}$ were intersected $0.5 \mathrm{~m} / \mathrm{s}^{2}$, respectively. Therefore, it can be concluded that the following TH at $90 \mathrm{~km} / \mathrm{h}$ was $1.2 \mathrm{sec}$ (men) and $2 \mathrm{sec}$ (woman). This has been estimated averagely 1.5 in the previous studies; $[4,27]$. This suggests that DS and age can also be effective in following distance threshold. 


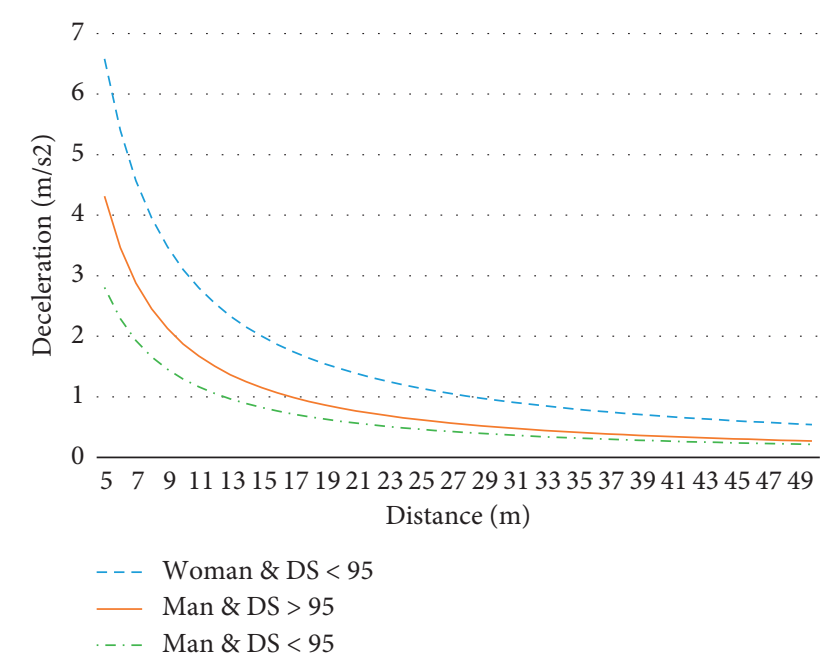

FIgURE 7: Relationship between deceleration and distance in different groups of drivers.

\section{Conclusion}

In this study, the effect of age, gender, and DS factors on CF behavior was investigated. DS was defined as the speed selected by the driver in free driving situation. A driving simulator was used to collect data. The CF model for each driver was calibrated by genetic algorithm. The estimated parameters were categorized based on the factors and analyzed using statistical tests. For further investigation, the effect of the DS factor on the TH in the steady-state CF was also examined. Considering the effect of factors, three GM CF models were provided and the threshold of the CF was investigated too.

The results of the research can be summarized as follows:

(i) Gender and DS were effective in CF behavior, while the age factor was not.

(ii) The sensitivity of drivers to the variables of speed and distance in the CF model increased with increasing the DS, while the magnitude of deceleration was higher in women.

(iii) DS factor was effective in steady-state CF behavior. As the DS increased, the TH decreased.

(iv) Women maintained larger CF threshold distance than men.

(v) The DS can be considered as an indicator for aggressive behavior in deceleration CF and steadystate CF behavior.

\section{Data Availability}

Data used in this study are available on request from the corresponding author.

\section{Conflicts of Interest}

The authors declare that they have no conflicts of interest.

\section{References}

[1] C. C. Minh and K. Sano, "Acceleration and deceleration models of motorcycle at signalized intersections," Journal of the Eastern Asia Society for Transportation Studies, vol. 7, pp. 2396-2411, 2007.

[2] J. Son et al., "1G-33 age and gender difference in driving style and fuel efficiency on highway driving," The Japanese Journal of Ergonomics, vol. 49, no. 1, pp. S548-S551, 2013.

[3] M. R. Fard and A. S. Mohaymany, "A copula-based estimation of distribution algorithm for calibration of microscopic traffic models," Transportation Research Part C: Emerging Technologies, vol. 98, pp. 449-470, 2019.

[4] E. Ramezani Khansari, F. Moghadas Nejad, and S. Moogehi, "Comparing time to collision and time headway as safety criteria," Pamukkale University Journal of Engineering Sciences, vol. 1000, no. 1000, 10 pages, 2020.

[5] R. Elvik, "Why some road safety problems are more difficult to solve than others," Accident Analysis \& Prevention, Elsevier, vol. 42, no. 4, pp. 1089-1096, 2010.

[6] E. L. Harbeck and A. I. Glendon, "How reinforcement sensitivity and perceived risk influence young drivers reported engagement in risky driving behaviors," Accident Analysis \& Prevention, vol. 54, pp. 73-80, 2013.

[7] A. T. McCartt, V. I. Shabanova, and W. A. Leaf, "Driving experience, crashes and traffic citations of teenage beginning drivers," Accident Analysis \& Prevention, vol. 35, no. 3, pp. 311-320, 2003.

[8] T. Özkan and T. Lajunen, "What causes the differences in driving between young men and women? The effects of gender roles and sex on young drivers driving behaviour and selfassessment of skills," Transportation research part F: Traffic psychology and behaviour, vol. 9, no. 4, pp. 269-277, 2006.

[9] D. F. Preusser, S. A. Ferguson, and A. F. Williams, "The effect of teenage passengers on the fatal crash risk of teenage drivers," Accident Analysis \& Prevention, vol. 30, no. 2, pp. 217-222, 1998.

[10] Q. Luo, "Research of vehicle rear-end collision model considering multiple factors," Mathematical Problems in Engineering, vol. 2020, Article ID 6725408, 11 pages, 2020.

[11] Q. Xue, "Uncertainty analysis of rear-end collision risk based on car-following driving simulation experiments," Discrete Dynamics in Nature and Society, vol. 2018, Article ID 5861249, 13 pages, 2018.

[12] E. Amini et al., "A vehicle type-based approach to model car following behaviors in simulation programs (case study: carmotorcycle following behavior)," IATSS Research, vol. 43, no. 1, pp. 14-20, 2018.

[13] A. Duret, C. Buisson, and N. Chiabaut, "Estimating individual speed-spacing relationship and assessing ability of Newells car-following model to reproduce trajectories," Transportation research record, vol. 2088, no. 1, pp. 188-197, 2008.

[14] E. R. Khansari, M. Tabibi, and F. Moghadas Nejad, "Lanebased car-following behaviour based on inductive loops," in Proceedings of the Institution of Civil Engineers-Transport, London, England, May 2017a.

[15] S. Ossen and S. Hoogendoorn, "Car-following behavior analysis from microscopic trajectory data, Transportation Research Record," Journal of the Transportation Research Board, vol. 34, pp. 13-21, 2005.

[16] S. Ossen and S. P. Hoogendoorn, "Driver heterogeneity in car following and its impact on modeling traffic dynamics," Transportation Research Record, vol. 199, no. 1, pp. 95-103, 2007. 
[17] S. Ossen and S. P. Hoogendoorn, "Heterogeneity in car-following behavior: theory and empirics," Transportation Research Part C: Emerging Technologies, vol. 19, no. 2, pp. 182-195, 2011.

[18] T. A. Ranney, "Psychological factors that influence car-following and car-following model development," Transportation research part F: traffic psychology and behaviour, vol. 2, no. 4, pp. 213-219, 1999.

[19] J. Montgomery, K. D. Kusano, and H. C. Gabler, "Age and gender differences in time to collision at braking from the 100-car naturalistic driving study," Traffic Injury Prevention, vol. 15, pp. S15-S20, 2014.

[20] R. M. James and B. E. Hammit, "Identifying contributory factors to heterogeneity in driving behavior: clustering and classification approach," Transportation research record, vol. 2673, no. 10, pp. 343-353, 2019.

[21] N. Chiabaut, L. Leclercq, and C. Buisson, "From heterogeneous drivers to macroscopic patterns in congestion," Transportation Research Part B: Methodological, vol. 44, no. 2, pp. 299-308, 2010.

[22] J. Kim and H. S. Mahmassani, "Correlated parameters in driving behavior models: car-following example and implications for traffic microsimulation," Transportation Research Record, vol. 2249, no. 1, pp. 62-77, 2011.

[23] C. P. I. J. van Hinsbergen, "Bayesian calibration of car-following models," IFAC Proceedings, vol. 42, no. 15, pp. 91-97, 2009.

[24] P. Ranjitkar, T. Nakatsuji, and M. Asano, "Performance evaluation of microscopic traffic flow models with test track data," Transportation Research Record, vol. 1876, no. 1, pp. 90-100, 2004.

[25] C. Chen, "Calibration of MITSIM and IDM car-following model based on NGSIM trajectory datasets," in Proceedings of 2010 IEEE International Conference on Vehicular Electronics and Safety, pp. 48-53, QingDao, China, July 2010.

[26] J. Taylor et al., "Method for investigating intradriver heterogeneity using vehicle trajectory data: a dynamic time warping approach," Transportation Research Part B: Methodological, vol. 73, pp. 59-80, 2015.

[27] E. R. Khansari, M. Tabibi, and F. M. Nejad, "A study on following behavior based on the time headway," Jurnal Kejuruteraan, vol. 32, no. 2, pp. 187-195, 2020.

[28] J. Appiah, "Bus following model: a case study in Edinburgh," International journal of transportation. Science and Engineering Research Support Society, vol. 3, no. 2, pp. 1-16, 2015.

[29] K. Bevrani, E. Chung, and M. Miska, "Evaluation of the GHR car following model for traffic safety studies," in Proceedings of the 25th ARRB Conference, ARRB Group Ltd, Port Melbourne, Australia, June 2012.

[30] E. R. Khansari, M. Tabibi, and F. Moghadas Nejad, "Lanebased car-following behaviour based on inductive loops," in Proceedings of the Institution of Civil Engineers-Transport, London, England, May 2017b.

[31] E. Ramezani Khansari, M. Tabibi, and F. Moghadas Nejad, "Studying non-coaxiality in non-lane-based car-following behavior," Civil Engineering Journal, vol. 4, no. 12, 2840 pages, 2018.

[32] T. Engen, Use and Validation of Driving Simulators, Norwegian University of Science and Technology, Trondheim, Norway, 2008.

[33] S. T. Godley, T. J. Triggs, and B. N. Fildes, "Driving simulator validation for speed research," Accident analysis \& prevention, vol. 34, no. 5, pp. 589-600, 2002.
[34] G. Underwood, D. Crundall, and P. Chapman, "Driving simulator validation with hazard perception," Transportation research part F: traffic psychology and behaviour, vol. 14, no. 6, pp. 435-446, 2011.

[35] E. Ramezani-Khansari, M. Tabibi, and F. Moghadas Nejad, "Validating driving simulator for car-following distance," Iranian Journal of Science and Technology, Transactions of Civil Engineering, vol. 45, no. 1, pp. 281-290, 2021.

[36] R. A. Overton, "Driving simulator transportation safety: proper warm-up testing procedures, distracted rural teens, and gap acceptance intersection sight distance design," 2012.

[37] T. Officials, A Policy on Geometric Design of Highways and Streets, American Association of State Highway and Transportation Officials, Washington, DC, USA, 2011. 